\title{
Aroma composition of commercial truffle flavoured oils: does it really smell like truffle?
}

\author{
E. Campo 1 ,a, S. Guillén ${ }^{1}$, P. Marco ${ }^{1}$, A. Antolín ${ }^{1}$, C. Sánchez ${ }^{1}$, R. Oria ${ }^{1}$ and D. Blanco ${ }^{1}$ \\ ${ }^{1}$ Instituto Universitario de Investigación Mixto Agroalimentario de Aragón (IA2) - Universidad de \\ Zaragoza / CITA. Facultad de Veterinaria. Zaragoza (Spain).
}

\begin{abstract}
The present study analyzes the aromatic and odour volatile profiles of truffle flavoured oils commercialized as "black truffle oil". The aim of this work is twofold: to define the sensory space associated to these products and to explore the possible fraudulent use of artificial flavouring agents not properly identified on the label. For this purpose, 12 commercial truffle flavoured oils available in the Spanish market were submitted to descriptive sensory analysis by a trained panel. The three oils presenting the most interesting profile (in terms of odour nature and/or complexity) were also analyzed by olfactometric analysis, in order to identify the chemical compounds responsible on their aroma. The correlation of sensory and olfactometric data made it possible to understand some of the sensory differences observed among samples, as well as to identify irregularities with respect to the ingredients labelling of some of the studied samples.
\end{abstract}

Keywords: commercial truffle oil, olfactometry, sensory analysis, ingredient labelling

\section{INTRODUCTION}

Truffles are subterranean fruity bodies produced by some species of fungi of the genus Tuber (Ascomycota, Pezizales). Due to its potent and complex aroma, and to the high prices they can reach in the fresh market. Truffle has longtime be employed as a natural flavouring agent of food products, olive oil being one of the most commonly used. Truffle oil is mainly elaborated with black truffle (Tuber melanosporum) or Alba white truffle (Tuber magnatum), and makes it possible to implement the typical aromas of such fungi on the produce. At present there are not standardized protocols for the elaboration of truffle oils, which means that each company follows their own procedures.

Several national and international gastronomic forums have highlighted the existing debate with respect to the use of truffle flavoured oils in gastronomy (http://blogs.elpais.com/gastronotas-de-capel/2012/02/todos-contra-el-aceite-de.html;

http://www.seriouseats.com/2011/04/rant-enough-with-the-truffle-oil-already.html. The authors behind these blogs, point out the exaggerate use of artificial flavouring agents that try to simulate the aroma of fresh truffle. José Carlos Capel, gastronomic critic and President of Madrid Fusion reflected this problematic on an article devoted to white truffle flavoured oils. In particular, he stated that "these oils mask the original flavour of noble row materials, as they are fat smelling of gas, garlic, hydrocarbons, mushroom and wet earth. Such product evokes aromas of much more intensity than the authentic white truffle". Such added ingredients, in general, are not reflected on the product label, which contributes to provide consumers a confusing image about what real black truffle actually smells like.

\footnotetext{
a emcampo@unizar.es
} 
Despite the subject has been brought to the attention of the public opinion, little scientific works have been devoted to explore the aroma of these products from a chemical viewpoint. Most of the works are from Italian authors: Fiecchi et al. (1967); Orilisi \& Benetti (1991); Piloni et al. (2005). More recently, Pacioni et al. (2014) have addressed the study of the composition of commercial truffle flavoured oils by means of GC-MS analysis, confirming the established malpractice of the use of bismethyl(dithio)methane. This compound, responsible for the characteristic aroma of white truffle (Tuber magnatum) is indeed used in excessive amounts to enhance the aroma of oils made from other truffle species, such as Tuber melanosporum and Tuber aestivum, which are characterized by completely different aroma notes.

Given the lack of standard legal practices to elaborate truffle flavoured oils, and the confusing information with respect to the labelling requirements and use of ingredients, the aim of this work is twofold:

1) To evaluate, from a sensory viewpoint, truffle flavoured oils labelled as "from black truffle" representative of the current Spanish market, with the aiming of characterizing their sensory space.

2) To study the volatile odour compounds (number and chemical nature) responsible for the oil aroma, and to detect eventual frauds with respect to the information present in the label.

\section{MATERIALS AND METHODS}

\section{Samples}

Twelve commercial truffle flavoured oils labelled as "black truffle oil" representative of the current Spanish market were purchased on a hypermarket at Zaragoza (Spain). These were produced in several Spanish regions: Soria (3), Teruel (2), Lérida (2), Barcelona (2), Madrid (1), Valencia (1) and Huesca (1). The range of prices of selected oils varied between 25 and 150 euros per liter. Fresh truffle and a regular commercial olive oil were employed as control samples in order to compare processed product (flavoured oil) vs. genuine row ingredients.

\section{Descriptive sensory analysis.}

Panel training and formal measurements. The panel of tasters was formed by 14 judges with previous experience in sensory analysis of truffle and/or oil. They panel was trained for the aromatic evaluation of truffle flavoured oils during twelve 1-h sessions along four months, following the ISONORM 11035 (1994) procedure.

In the first session, the tasters evaluated a total of 10 truffle commercial oils and generated the terms most appropriate to describe their aroma. Once all the terms were compiled, this preliminary list was presented to the panelists on a second session, which asses the attributes on the same oils, this time using a 10 point scale. Principal component analysis was run in order to visualize correlations among terms (synonyms and antonyms), and results were shown to panelists on a third session. This was divided in two parts. First, judges compared their individual responses of the former session with the average value given by the rest of panelists, which helped in concept alignment. Second, the panel discussed the pertinence of the evaluated terms and agreed on the terms of the final list, which included: "aroma balance", "rancid", "artificial", "mold", "truffle", "olive", "garlic", 
"fermentation" and "characteristic truffle aroma". On session four, different commercial truffle flavoured oils were used as aroma references to illustrate the terms on the list. In case of disagreement among panelists, a discussion was stablished till a consensus was achieved. Sessions five and six were devoted to the evaluation of 6 truffle oils (in duplicate; 1 replicate per session). From these data, judge performance was checked regarding the ability to discriminate among products, reproducibility and homogeneity of the panel in the use of descriptors as described in Campo et al. (2010). Based on these indicators, the panel was deemed successfully trained. Finally, in sessions seven to ten panelists evaluated the 12 oils from the study, in duplicate (6 samples per session).

Sample presentation. In all cases, oil samples were presented in clear plastic spoons labeled with 3-digit codes. Panellists were encourage to clean the palate with mineral water and bread and/or apple among samples. Oil samples were presented simultaneously according to the William Latin-square arrangement in order to reduce biases related to the order, carry-over or expectation effects (MacFie et al. 1989). Sessions took place in individual booths and lasted approximately $45 \mathrm{~min}$. A 10 -min break was enforced in the middle of each session to limit judge fatigue.

Data analysis. Sensory data was analyzed by means of Principal Component Analysis (PCA). Standardised PCA was performed on the mean ratings among the judges for all attributes (correlation matrix) using data of all the truffle oil samples by means of SPAD software (version 5.5, CISIA-CERESTA, Montreuil, France).

\section{Analysis of odour volatile compounds}

Extraction of volatiles by SPME. Volatile compounds from the truffle oil were captured in a solid-phase microextraction fiber (SPME) coated with a 50/30 $\mu \mathrm{m}$ DVB/CX/PDMS layer (Supelco, Barcelona). Five $\mathrm{mL}$ of oil were placed in a $15 \mathrm{~mL}$ glass vial closed with a septum. The vial was conditioned at $45{ }^{\circ} \mathrm{C}$ during $5 \mathrm{~min}$. After this time the fiber was exposed to the headspace of the oil during $40 \mathrm{~min}$. The sample was constantly stirred at $250 \mathrm{rpm}$. The extraction of volatiles from fresh truffle was performed following the procedure detailed in Diaz et al. (2003) with some modifications. Two grams of truffle finely sliced (around $2 \mathrm{~mm}$ thick) was placed in a $15 \mathrm{~mL}$ glass vial closed with a septum. This was conditioned at $53^{\circ} \mathrm{C}$ during 5 min.

Chromatographic analysis. In all cases, GC-O analysis was performed immediately after sampling. Thermal desorption of the fiber coating in the GC injector took place at 220 ${ }^{\circ} \mathrm{C}$ during $5 \mathrm{~min}$. The analysis was carried out in a gas chromatograph HP 4890 with a flame ionization detector (FID) and an olfactometric port. This instrument was equipped with a capillary column DB-WAX (polyethylene glycol) from J\&W Scientific, $30 \mathrm{~m} 0.32 \mathrm{~mm}$ i.d., 0.5 $\mu \mathrm{m}$ film thickness, and a pre-column ( $3 \mathrm{~m} \times 0.32 \mathrm{~mm}$ i.d.) from Supelco. The oven temperature program was the following: $40{ }^{\circ} \mathrm{C}$ for $5 \mathrm{~min}$, then raised at $5^{\circ} \mathrm{C} \mathrm{min}^{-1}$ to $220^{\circ} \mathrm{C}$ and at $6^{\circ} \mathrm{C}$ min $^{-1}$ to $220^{\circ} \mathrm{C}$, followed by $20 \mathrm{~min}$ at $220^{\circ} \mathrm{C}$. Injector and detector were kept at $220^{\circ} \mathrm{C}$.

Olfactometry. A panel of six judges (three women and three men, ranging from 23 to 38 years of age), carried out the sniffing of the volatile compounds. They were asked to provide a descriptor to characterize the eluted odor and to rate its intensity using a 3-point category scale $(0=$ no odour; $3=$ very strong odour). The odorants were identified by comparison of their odors and chromatographic retention index in DB-WAX column with those of pure reference compounds injected under the same conditions. Additionally, the identity of 
compounds was checked by comparing the sequence of LRI with that of other published databases. In particular, we used the database compiled for Styrian pumpkin seed oil (Poehlmann \& Schieberle, 2013), as many of our target, low-odour threshold volatiles were previously detected in samples of this pumpkin seed oil.

Data analysis. The data processed were a mixture of the intensity and the frequency of detection of an odorant. This parameter is labeled "modified frequency" (MF) and is calculated with the formula proposed by Dravnieks (1985); MF $(\%)=\left[\mathrm{F}(\%)^{*} \mathrm{I}(\%)\right]^{1 / 2}$, where $\mathrm{F}(\%)$ is the detection frequency of an aromatic odorant expressed as percentage of total number of judges and I (\%) is the average intensity expressed as percentage of the maximum intensity. This parameter makes it possible to establish a hierarchy of the volatile compounds most relevant in the aroma of each of the studied oils as detailed in Campo et al. (2005). The different odour notes detected in the GC-O experiment; odour descriptor, chemical identity, linear retention index, retention time, and modified frequency (\%) of these odour zones for the five samples; fresh truffle, virgin olive oil, and flavoured oils number 6, 9 and 12 were calculated.

\section{RESULTS AND DISCUSSION}

\section{Descriptive sensory analysis}

The projection of the sensory variables on the plane formed by Principal Components 1 and 2 (63\% of the total variance) is presented in Figure 1. The first component (34\%) contrasts the typical truffle flavour (both perceived ortho- and retronasally) and the aroma and taste balance against the rancid and moldy notes. The second component $(29 \%)$ contrasts the black olive notes, to the garlic and artificial-like odours, both with a manifest negative connotation.

Figure 1) Correlation circle for sensory descriptors in PCA

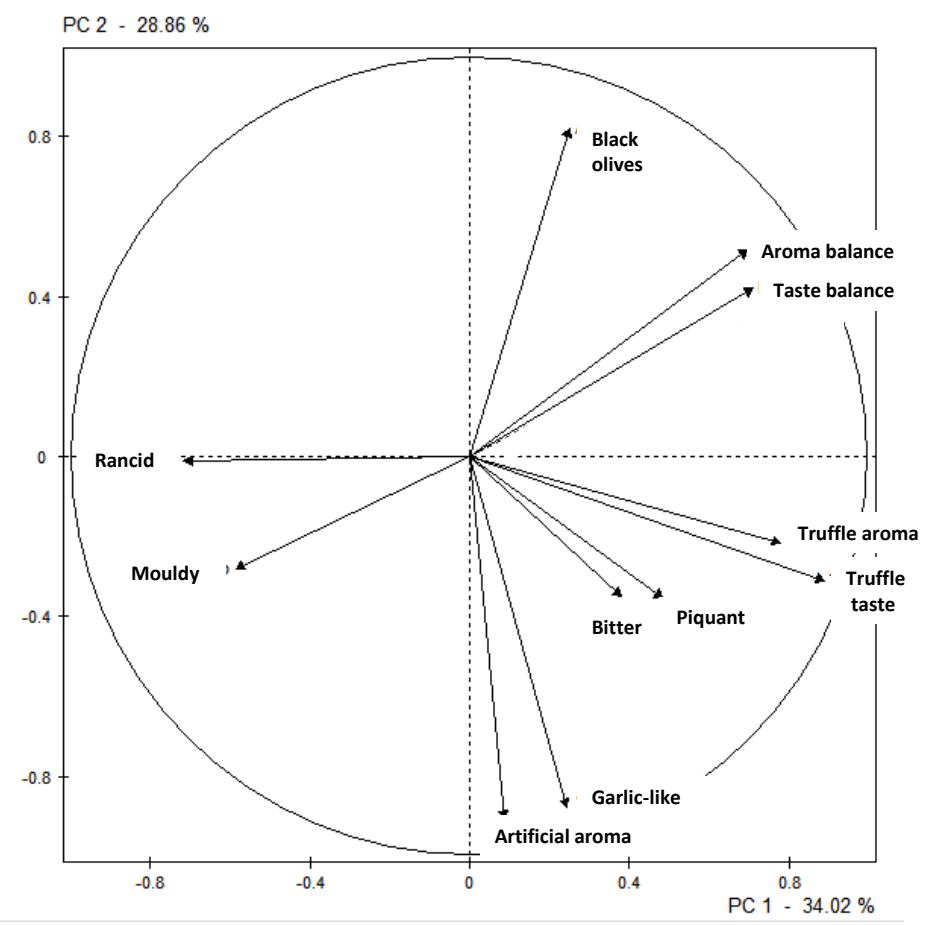


Figure 2. Projection of oils in the PCA plot (encircled samples were selected for GC-O analysis).

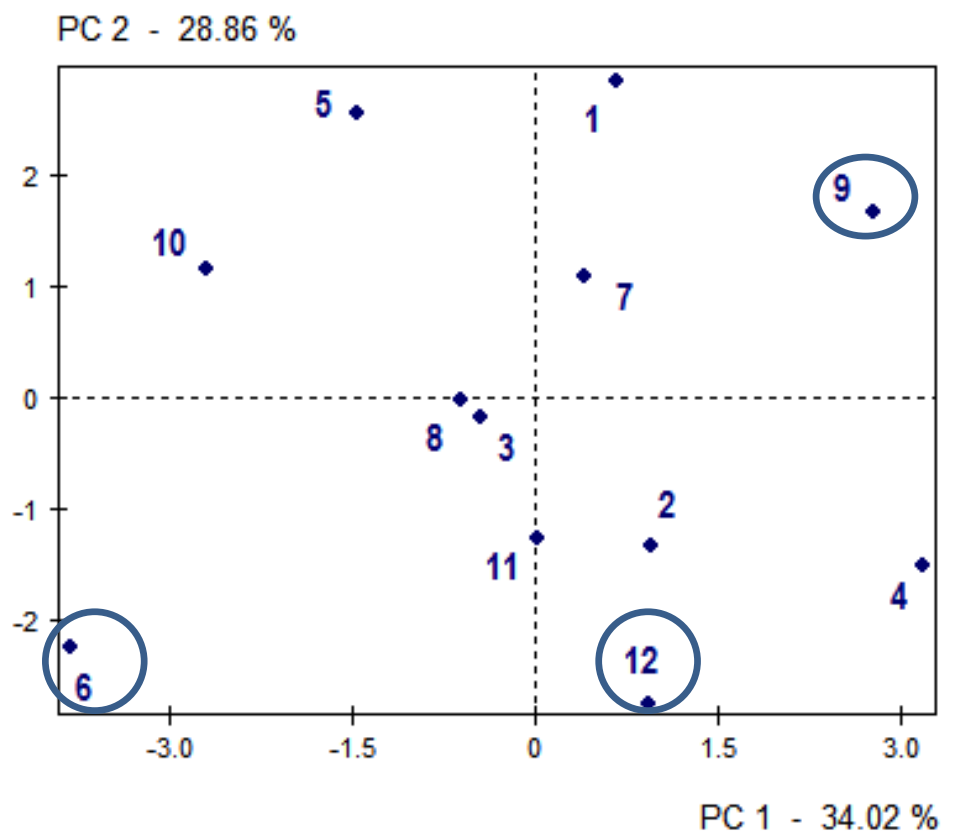

The projection of oils in the bi-dimensional plot is presented in Figure 1b. As can be seen, samples are scattered over the map, which provides an idea of the variability on the sensory profiles of the studied oils, and a first picture of the sensory space of commercial oils currently present in the market. The three samples projected on the edges of the plot $(6,9$ and 12) presented particularly interested profiles, in terms both of odour nature and/or complexity. Sample 9 showed the best "flavour balance", and was characterized both by "black olives" and "truffle aroma", as shown in the correlation circle (Fig. 1a). This oil was therefore considered as the closer one to the genuine "fresh truffle" concept. Sample 6 evoked a totally different profile, and indeed was projected on the opposite side of the PCA plot, characterized by the moldy and artificial odours. Finally, sample 12 presented an intense artificial and garlic-like odours, and slight truffle notes.

\section{Analysis of odour volatiles and correlation to descriptive aroma profiles}

Compared to raw ingredients ("fresh truffle" and "regular olive oil", the overall profiles of truffled oils were less complex (Table 1). The aroma of fresh black truffle was composed by a variety of odorants belonging to diverse chemical families: sulphur compounds, ethyl esters, saturated and unsaturated aldehydes, pyrazynes, alcohols and volatile phenols. Results on black truffles are in agreement with those previously reported by Cullere et al. (2010) in Tuber melanosporum samples analyzed by a SPME and olfactometric strategy.

None of the oils presented highly volatile molecules. Dimethylsulfide (DMS) and dimethyldisulfide (DMDS) are sulphur compounds with a potent aroma of black olives that were only detected in truffle. Ethyl ester compounds, evoking strawberry aromas, were detected in both truffle and virgin olive oil, but not on the flavoured oils. Similarly, important key-compounds of olive oil such as $\beta$-phenylethyl acetate and $\beta$-phenylethanol, both with typical rose-like odours, were not present in any of the flavoured oils studied. 
Table 1. Odorants found by GC-O in the studied samples; olfactory description, chemical identity, gas chromatographic retention data (linear retention index and time) and modified frequency percentage (\%MF).

\begin{tabular}{|c|c|c|c|c|c|c|c|c|}
\hline Aroma descriptor & Compound & LRI & Rt & $\begin{array}{l}\text { Fresh } \\
\text { truffle }\end{array}$ & $\begin{array}{l}\text { Regular } \\
\text { Olive oil }\end{array}$ & AT_6 & AT_9 & AT_12 \\
\hline Black olives, truffle & Dimethylsulfide & $<900$ & 3.53 & 84 & - & - & & - \\
\hline Black olives, truffle & Dimethyldisulfide & 915 & 5.59 & 97 & - & - & - & - \\
\hline Whipped cream & 2,3-butanodione & 989 & 8.15 & 66 & 100 & - & - & - \\
\hline Strawberry & Ethyl 2-methylbutyrate & 1066 & 10.45 & 93 & 82 & - & - & - \\
\hline Strawberry, pineapple & Ethyl isovalerate & 1074 & 11.01 & 51 & 35 & - & - & - \\
\hline Grass & Z-3-hexenal & 1149 & 13.57 & - & 91 & 51 & - & - \\
\hline Fish & Z-4-heptenal & 1256 & 17.30 & - & 41 & - & - & - \\
\hline Garlic & $\mathrm{Ni}$ & 1300 & 18.57 & - & - & 52 & - & - \\
\hline Truffle & $\mathrm{Ni}$ & 1306 & 19.09 & - & - & - & 98 & 94 \\
\hline Garlic & Bis(methylthio)methane & 1317 & 19.30 & - & - & 100 & - & 53 \\
\hline Mushroom & 1-octen-3-one & 1319 & 19.33 & 50 & - & 97 & 100 & 95 \\
\hline Popcorn & 2-acetyl-1-pyrroline & 1360 & 20.49 & 17 & - & - & 20 & 84 \\
\hline Geranium & Z-1,5-octadien-3-one & 1394 & 21.53 & - & 29 & - & 34 & - \\
\hline Boiled fish & $\mathrm{Ni}$ & 1453 & 23.36 & - & - & 49 & - & \\
\hline Vinegar & Acetic acid & 1470 & 24.06 & 42 & 71 & - & - & - \\
\hline Boiled potato & 3-(methylthio)propanal & 1482 & 24.27 & 33 & - & - & - & - \\
\hline Roquefort cheese & $\mathrm{Ni}$ & 1555 & 26.28 & 67 & - & - & - & - \\
\hline Green pepper & $\begin{array}{l}\text { 3-isobutyl-2- } \\
\text { methoxypyrazine }\end{array}$ & 1570 & 26.53 & 52 & - & - & - & - \\
\hline Garlic & $\mathrm{Ni}$ & 1604 & 27.48 & - & - & 99 & - & - \\
\hline Cucumber & E,Z-2,6-nonadienal & 1624 & 28.19 & 51 & - & - & - & - \\
\hline Toasted bread & Acetylpyrazine & 1651 & 29.00 & - & - & 18 & 34 & - \\
\hline Chickpea, broth & E,Z-2,4-nonadienal & 1721 & 30.47 & 50 & & - & - & - \\
\hline Roses & $\beta$-phenylethyl acetate & 1725 & 30.53 & - & 41 & - & - & - \\
\hline Honey & Ethyl phenylacetate & 1768 & 31.57 & - & - & - & - & - \\
\hline Rancid & E,E-2,4-nonadienal & 1797 & 32.39 & 23 & 34 & - & - & - \\
\hline Floral & $\beta$-phenylethanol & 2000 & 37.23 & 53 & 41 & - & - & - \\
\hline Smoky & 3-ethylphenol & $>2000$ & 42.15 & 54 & - & - & - & - \\
\hline Dried peach & $\delta$-decalactone & $>2000$ & 43.03 & 54 & - & - & - & - \\
\hline
\end{tabular}

On the contrary, there are several odour zones that were exclusively detected by judges on some of the truffle oils. Only one compound, 1-octen-3-one, is common to truffle and the three studied oils. This ketone is a well-known compound of different species of truffle and other eatable fungi, with a potent and characteristic odour of mushroom. Another compound, 2-acetyl-pyrroline (popcorn aroma) was shared by fresh truffle and two of the oils (samples 9 and 12).

Special attention deserves three odour zones described as "garlic" from diverse volatility (LRIs 1300, 1317 and 1604). They were perceived as very intense by judges, with olfactometric scores as high as 52, 100 and 100, respectively. These means that the two latter odour zones were perceived by all judges, with the maxima intensity, which gives an idea of the relevance of the garlic-like odour family on this sample.

Comparing the GC-O profiles of samples 9 and 12 it can be seen that judges identified as very intense (almost $100 \%$ of MF) an odorant with truffle aroma, that could not be identified 
(LRI=1306). This odorant was not present in sample 6, neither in the genuine fresh black truffle.

Regarding bis(methylthio)methane (garlic odour), it was present in samples 6 (100\% MF) and 12 (53 \% MF). It can be hypothesized that the major differences in the sensory profile previously observed between sample 9 (perceived as the one with a more genuine fresh odour) and samples 6 and 12 (evoking garlic and artificial aroma) could be explained by the presence of this molecule in the former (Pelusio et al. (1995); Piloni et al. (2005); Pacioni et al. (2014)).

This compound is well-known as the key odorant of white truffle (Tuber magnatun Pico (Fiecchi et al. 1967), which indicates that it has been added as aromatic ingredient to the truffle oil. This practice, besides being unfair if not stated on the label, can totally ruin the overall sensory profile of the oil.

A major implication of this result is that producers should optimize their methodologies to implement natural aromas from the truffle on the oils, in order better reflect the aroma of genuine truffle. It would be, therefore, very convenient to create a legal frame to define the elaboration procedures of truffle flavoured oils, in order to limit the commercial frauds currently observed.

\section{CONCLUSIONS}

Commercial truffle flavoured oils present in the current Spanish market evoked, in general, little to no genuine black truffle aroma. On the contrary, most of them evoked garlic-like aromas and manifest defects, far from the fresh truffle concept. The olfactometry explained some of the sensory differences observed among samples, identifying important odour markers with a major role on the aroma.

\section{ACKNOWLEDGEMENTS}

This work has been funded by the Department of Industry and Innovation of the Aragon Government and the European Social Fund (Project 229402/1 - Plant Food Research Group).

\section{₹GOBIERNO}

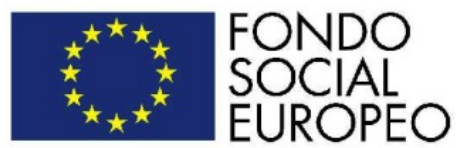

\section{Literature cited}

Campo, E., Ferreira, V., Escudero, A. and Cacho, J. (2005).Prediction of the wine sensory properties related to grape variety from dynamic-headspace gas chromatography-olfactometry data. J. Agric. Food Chem. 53, 56825690. DOI: 10.1021/jf047870a.

Campo, E., Ballester, J., Langlois, J., Dacremont, C. and Valentin, D. (2010). Comparison of conventional descriptive analysis and a citation frequency-based descriptive method for odor profiling: an application to Burgundy Pinot noir wines. Food Qual. Prefer. 21, 44-55. DOI: 10.1016/j.foodqual.2009.08.001.

Culleré, L., Ferreira, V., Chevret, B., Venturini, M.E., Sánchez-Gimeno, A.C., and Blanco, D., (2010). Characterization of aroma active compounds in black truffles (Tuber melanosporum) and summer truffles (Tuber aestivum) by gas chromatography-olfatometry. Food Chem. 122, 300-306. DOI: 10.1016/j.foodchem.2010.02.024

Dravnieks, A. Atlas of odor character profiles (1985).; Ed.; ASTM: Philadelphia, 354-356.

Fiecchi, A., Kienle, M.G., Scala, A., and Cabella, P. (1967). Bismethylthiomethane, an odorous substance from white truffle, Tuber magnatum Pico. Tetrahedron Lett. 8, 1681-1682. WOS:A19679259500001.

ISO 11035, 1994. Sensory Analysis: Identification and Selection of Descriptors for Establishing a Sensory Profile by a Multidimensional Approach. International Organization for Standardization, Geneva, Switzerland. 
MacFie, H., Bratchell, N., Greenhoff, K. and Vallis, L.V. (1989). Designs to balance the effect of order of presentation and first order carry-over effects in hall tests. J. Sens. Stud. 4, 129-148. DOI: 10.1111/j.1745459X.1989.tb00463.x

Orilisi, S. and Benetti, E. (2005). On the presence of bis(methylthio) methane in oils flavoured with truffle: determination GC/MS. Industrie Alimentari 30 (299): 1062-1065.

Pacioni, G., Cerretani, L., Procida, G., Cichelli, A. (2014). Composition of commercial truffle flavored oils with GCMS analysis and discrimination with an electronic nose. Food Chem. 146, 30-35. DOI: 10.1016/j.foodchem.2013.09.016.

Pelusio, F., Nilsson, T., Montanarella, L., Tilio, R., Larsen, B., Facchetti, S. and Madsen, F. (1995). Headspace solidphase microextraction analysis of volatile organic sulphur compounds in black and white truffle aroma. J. Agric. Food Chem. 43, 2138-2143, DOI: 10.1021/jf00056a034.

Piloni, M., Tat, L., Tonizzo, A., Battistutta, F. (2005). Aroma characterisation of white truffle by GC-MS and GC-O. Italian J. Food Sci. 17, 463-468. WOS:000234748100010

Poehlmann, S., \& Schieberle, P. (2013). Characterization of the aroma signature of styrian pumpkin seed oil (cucurbita pepo subsp. Pepo var. Styriaca) by molecular sensory science. J. Agric. Food Chem. 61, 2933-2942. Doi: 10.1021/jf400314j. 